Case report

\title{
Accessory liver fissures: a report of two cases and review of their clinical significance
}

\author{
Serghei Covanțev, Natalia Mazuruc, Ilia Catereniuc, Olga Belic \\ State University of Medicine and Pharmacy «Nicolae Testemițanu», Chișinau, Republic of Moldova
}

Received 4 November 2017, Accepted 17 December 2017

C 2017, Covanțev S., Mazuruc N., Catereniuc I., Belic O.

(C) 2017, Russian Open Medical Journal

Abstract: The advances of our knowledge of the anatomical structure of the liver led to the development of complicated interventional procedures, which have became more widely used in the last decades. Accessory liver fissures are a frequent anomaly that can lead to complications during diagnostic and surgical procedures. In our article, we present a description of two cases of accessory liver fissures and a review of their clinical significance.

Keywords: accessory liver fissure, hepatic artery, cystic artery

Cite as Covanțev S, Mazuruc N, Catereniuc I, Belic O. Accessory liver fissures: a report of two cases and review of their clinical significance. Russian Open Medical Journal 2018; 7: e0303.

Correspondence to Serghei Covantev. E-mail: Kovantsev.s.d@gmail.com.

\section{Introduction}

The advances of our knowledge of the anatomical structure of the liver led to the development of complicated interventional procedures that became more widely used in the last decades. Successful realization of surgical procedures depends on the detailed knowledge of the variations and anomalies of the liver [1]. Accessory liver fissures (ALF) are one of these anomalies that can lead to complications during and/or after diagnostic and surgical procedures.

The first description of ALF is probably attributed to Zahn in 1882. The so-called "Zahn grooves" can be found on the diaphragmatic liver surface and predominantly on the right liver lobe. This condition was explained by anatomical variability and the effects of pressure of the ribs and/or the diaphragm muscle [2]. Chronic lung conditions (chronic obstructive pulmonary disease, asthma, chronic bronchitis, pulmonary tuberculosis etc.) with cough as the predominant symptom could explain diaphragm hypertrophy, which leads us to another name for this condition "Cough furrows" [3]. Later, it was demonstrated, that these fissures are encountered frequently, so they do not represent a rare finding [4]. Another condition from the previous era that can cause ALF is prolonged wearing of a corset - "Corset liver" or "Ribbed liver" [5]. Thus, the presence of the fissures on the liver surface may indicate an underlying condition.

The incidence of some of these findings is high and this should be taken in consideration by healthcare providers to avoid misdiagnosis.

\section{Case report}

During the dissection of two abdominal organ complexes, we identified two cases of ALF.

In the first case, the liver had two accessory fissures and an unusual cystic artery. The first fissure was on the upper lateral part of diaphragmatic surface of the right lobe. It measured $7.6 \mathrm{~cm}$ and extended on $1 \mathrm{~cm}$ into the liver parenchyma (Figure 1). The second fissure divided the caudate lobe into two halves. It measured 4.5 $\mathrm{cm}$ and extended on $1.5 \mathrm{~cm}$ into the liver parenchyma (Figure 2). Vascular anatomy of the liver was normal, except for the cystic artery that had two separate origins: one - from the common hepatic artery and the second - from the gastroduodenal artery. Then the arteries united in a form of a triangle (Figure 2).

The second case was present in male cadaver of 67 years. Two accessory fissures were present on the diaphragmatic surface of the liver, one on the caudate lobe and one on the right lobe (Figure 3). The first accessory fissure had a length of $4.8 \mathrm{~cm}$ and extended $0.8 \mathrm{~cm}$ into the liver parenchyma. The second accessory fissure was $3.8 \mathrm{~cm}$ and extended $0.3 \mathrm{~cm}$ into the liver. The ALF of the caudate process measured $3 \mathrm{~cm}$ and extended $1.2 \mathrm{~cm}$ in the liver. The last ALF measured $4.1 \mathrm{~cm}$ and extended $0.8 \mathrm{~cm}$ in the parenchyma (Figure 4). The arterial supply was by the proper hepatic artery that branched into left and right hepatic arteries supplied the liver. An intermediate branch arose from the left hepatic artery (Figure 4).

\section{Discussion}

The incidence of ALF is high and this should be taken in consideration by healthcare providers to avoid misdiagnosis.

ALF can be present on any lobe of the liver. It seems that they are more frequently encountered on the right lobe, followed by quadrate lobe [6]. Interestingly, they can be seen in $6-53 \%$ of cases, although, the data about this anomaly is not abundantly present in the literature $[6,7]$. ALF are in $47 \%$ multiple (from 2 to 6) $[8,9]$. Their frequency increases with age, approaching $70 \%$ in the seventh and eighth decades. Their depth may equal or exceed $2 \mathrm{~cm}$ in one-third of cases [10]. 


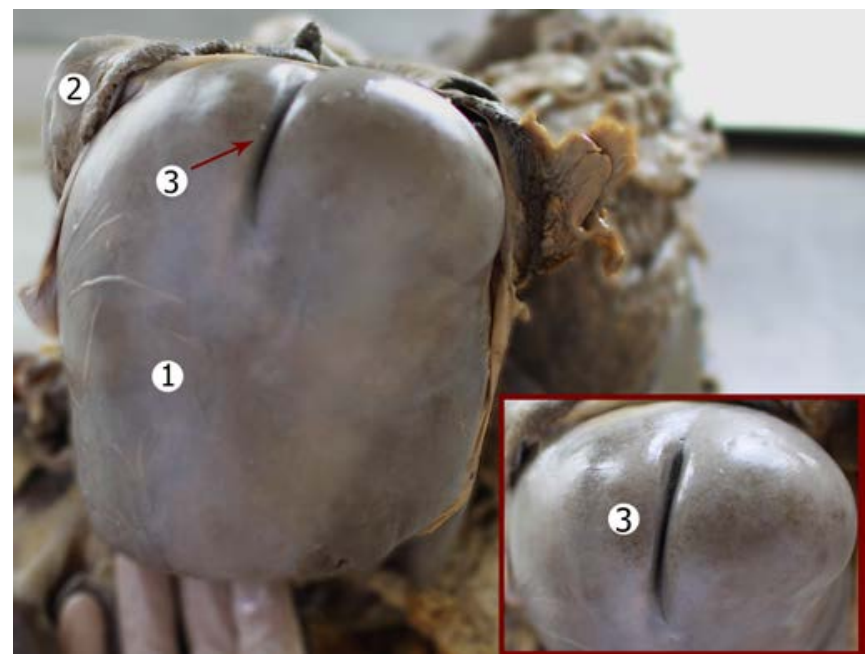

Figure 1. Lateral part of diaphragmatic liver surface. Macro specimen, male 60 years. 1 - right liver lobe; 2 - diaphragm, 3 - accessory liver fissure.

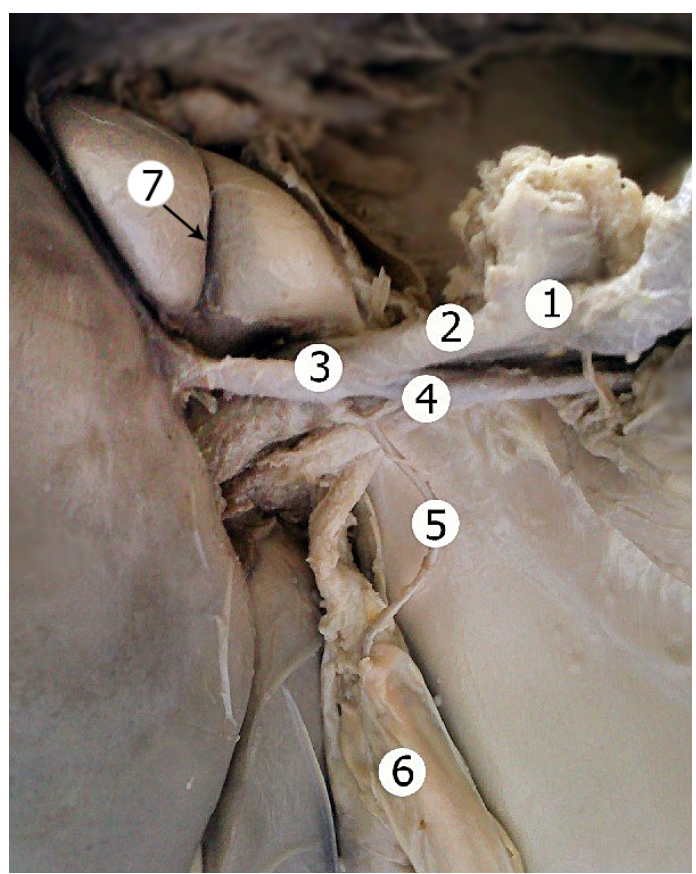

Figure 2. Visceral liver surface. 1 - celiac trunk; 2 - common hepatic artery; 4 - gastroduodenal artery; 5 - cystic artery; 6 - gallbladder; 7 accessory liver fissure.

Macchi and coworkers demonstrated by radiological images and corrosion casts that there is a correspondence between sulci and the right hepatic vein and the right portal fissure in $71 \%$ of cases. Thus, the main accessory sulcus develops along a theoretically predictable course, corresponding to the superficial part of the right portal fissure. This area may represent a watershed between the roots of the tributaries of the hepatic veins, coming from segments VIII and VII, draining respectively into the middle and right hepatic veins [8]. The reason for this is, probably, the pressure, exerted by the diaphragm as a whole but not by the individual hypertrophied branches [9].

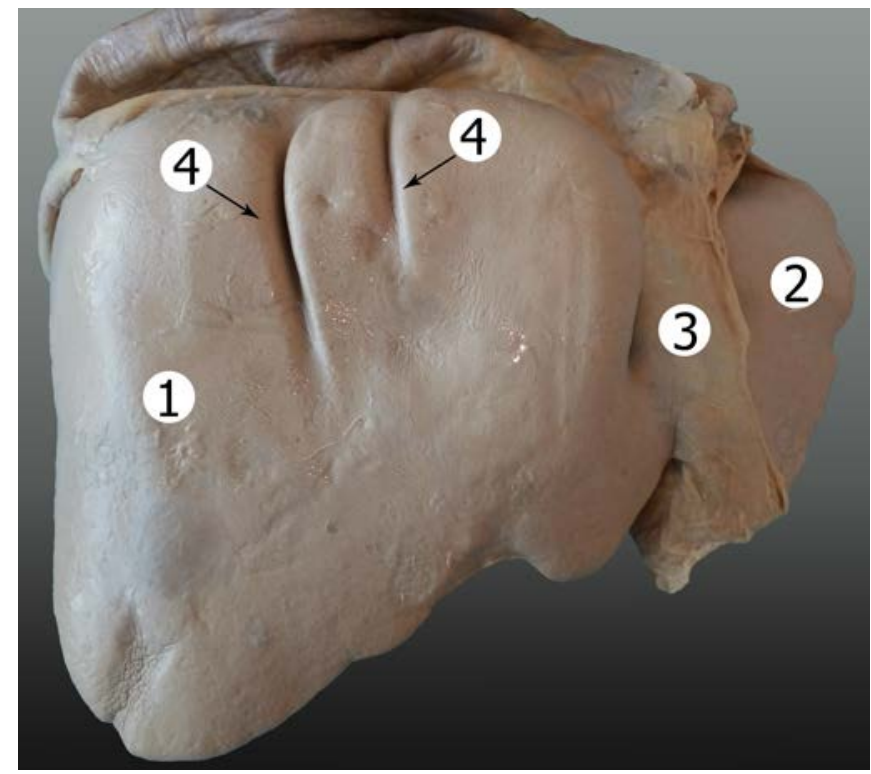

Figure 3. Two accessory fissures on the right lobe of the liver. Macro specimen, male 67 years. 1 - right liver lobe; 2 - left liver lobe; 3 falciform ligament; 4 - two accessory fissures.

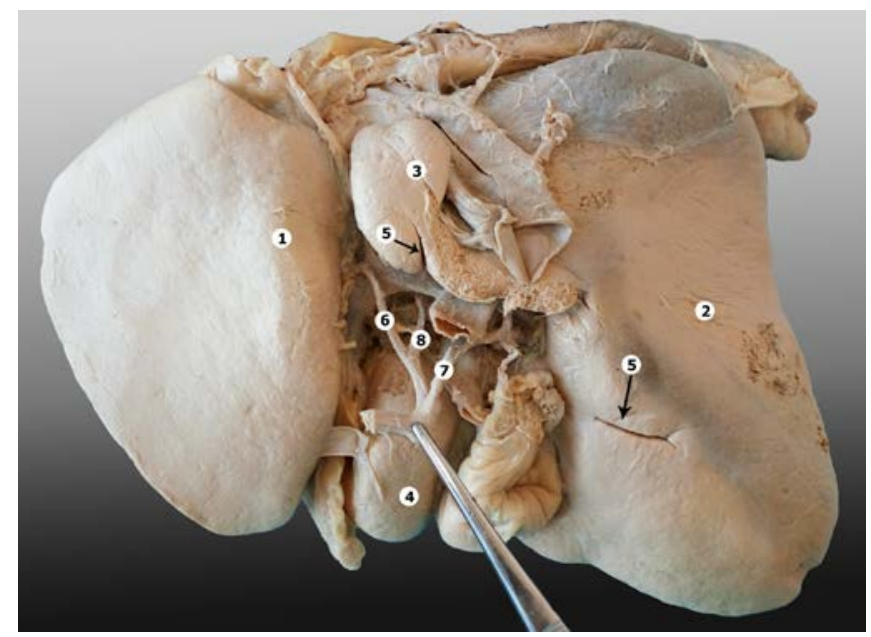

Figure 4. A fissure that divides the caudate lobe of the liver. 1 - left liver lobe; 2 - right liver lobe; 3 - caudate lobe; 4 - quadrate lobe; 5 - accessory liver fissure; 6 - left hepatic artery; 7 - right hepatic artery; 8 intermediate hepatic artery.

Although there is limited data on this frequently encountered anomaly the extent of its clinical significance is impressing.

When ascites, hemoperitoneum, or infected ascites is located in the fissures, it may be mistaken for a liver cyst, intrahepatic hematoma, or liver abscess. When peritoneally disseminated tumor cells are implanted into these spaces, they may mimic intrahepatic focal lesions [11].

This condition can also mimic liver malformations, nodules and sometimes tumors $[10,12]$. It can also cause alteration of hepatic perfusion resulting in pseudolesions on computed tomography [13]. 
There is data that demonstrate that minor grooves between segment $\mathrm{V}$ and $\mathrm{VI}$ and segment $\mathrm{V}$ and $\mathrm{VI}$ can be used to perform monosegmentectomy and thus are helpful to determine the resection margin for non-anatomical resection [14].

Finally, in cases of abdominal trauma, imaging studies or direct palpation of sulcus during laparotomy may give a false impression of a liver laceration [3]. The presence of ALF may also be the reason for unnecessary surgical procedures.

\section{Conclusion}

We presented two cases of ALF with a review of their clinical significance in medical practice. Taken in consideration the incidence of this finding, as well as limited data on the subject it is important for physicians to be aware of this variant of development.

\section{Conflict of interest}

The authors declare that they have no conflict of interests.

\section{References}

1. Skandalakis JE, Skandalakis LJ, Skandalakis PN, Mirilas P. Hepatic surgical anatomy. The Surgical Clinics of North America 2004; 84(2): 413-435, viii. http://dx.doi.org/10.1016/j.suc.2003.12.002.

2. Zahn FW. Note sur les plis respiratoires du diaphragme et les sillons diaphragmatiques du foie. Rev Méd Suisse Romande 1882; 2: 531-535.

3. Yadav GD, Deka P. Accessory sulcus of the liver - an incidental laparotomy finding. Indian J Surg 2008; 70(2): 92-93. http://dx.doi.org/10.1007/s12262-008-0025-9.

4. Ono ML, Murakami G, Sato TJ, Sawada K. Hepatic grooves and portal segmentation. Kaibogaku Zasshi 2000; 75(6): 517-523. https://www.ncbi.nlm.nih.gov/pubmed/11197594.

5. Philips DM, LaBrecque DR, Shirazi SS. Corset liver. J Clin Gastroenterol 1985; 7(4): 361-368. https://www.ncbi.nlm.nih.gov/pubmed/3900190.

6. Vinnakota $S$, Jayasree N. A new insight into the morphology of the human liver: a cadaveric study. ISRN Anatomy 2013; 2013: 689564. http://dx.doi.org/10.5402/2013/689564.

7. Joshi SD, Joshi SS, Athavale SA. Some interesting observations on the surface features of the liver and their clinical implications. Singapore Med J 2009; 50(7): 715-719. https://www.ncbi.nlm.nih.gov/pubmed/19644629.

8. Macchi V, Porzionato A, Parenti A, Macchi C, Newell R, De Caro R. Main accessory sulcus of the liver. Clin Anat 2005; 18(1): 39-45. https://doi.org/10.1002/ca.20030.

9. Macchi V, Feltrin G, Parenti A, De Caro R. Diaphragmatic sulci and portal fissures. J Anat 2003; 202(Pt 3): 303-308. https://dx.doi.org/10.1046\%2Fj.1469-7580.2003.00160.x.

10. Auh YH, Rubenstein WA, Zirinsky K, Kneeland JB, Pardes JC, Engel IA, et al. Accessory fissures of the liver: $\mathrm{CT}$ and sonographic appearance. $A J R$ Am J Roentgenol 1984; 143(3): 565-572. https://doi.org/10.2214/ajr.143.3.565.

11. Auh YH, Lim JH, Kim KW, Lee DH, Lee MG, Cho KS. Loculated fluid collections in hepatic fissures and recesses: CT appearance and potential pitfalls. Radiographics 1994; 14(3): 529-540. https://doi.org/10.1148/radiographics.14.3.8066268.

12. Bornet G, Chancelier MD, Convard JP, Gignier P, Hamrouni A, Hovasse C, et al. "Corset liver": syndrome from a past era? J Radiol 2011; 92(10): 939-941. https://doi.org/10.1016/i.jradio.2011.05.012.

13. Yoshimitsu $K$, Honda $H$, Kuroiwa $T$, Irie $H$, Tajima $T$, Jimi $M$, et al. Pseudolesions of the liver possibly caused by focal rib compression: analysis based on hemodynamic change. AJR Am J Roentgenol 1999; 172(3): 645-649. https://doi.org/10.2214/ajr.172.3.10063852.
14. Lee JH, Lee SY, Hwang DW, Park KM, Lee YJ. Practical usefulness of minor grooves of the hepatic surface for liver resection. Hepatogastroenterology 2012; 59(114): 458-460. https://doi.org/10.5754/hge11415.

\section{Authors:}

Serghei Covanțev - MD, BEc, Specialist, State University of Medicine and Pharmacy "Nicolae Testemițanu", Chisinau, Republic of Moldova. http://orcid.org/0000-0001-7236-5699.

Natalia Mazuruc - Specialist, State University of Medicine and Pharmacy "Nicolae Testemițanu", Chisinau, Republic of Moldova. http://orcid.org/0000-0003-0610-5404.

Ilia Catereniuc - MD, PhD, Professor, Department of Human Anatomy, State University of Medicine and Pharmacy "Nicolae Testemițanu", Chisinau, Republic of Moldova.

Olga Belic - MD, PhD, Associate Professor, Department of Human Anatomy, State University of Medicine and Pharmacy "Nicolae Testemitanu", Chisinau, Republic of Moldova. 